\title{
DESTITUIÇÃO DO PODER FAMILIAR, MARCADORES SOCIAIS E PRECARIEDADE DOS ESPAÇOS PRIVADOS: ANÁLISE DISCURSIVA DE PETIÇÃO DO MINISTÉRIO PÚBLICO
}

\author{
Ângela Daltoé Tregnago ${ }^{1}$ \\ Thaís Janaína Wenczenovicz ${ }^{2}$
}

Resumo: No Brasil, quase 27 milhões de crianças e adolescentes (49,7\% do total) têm um ou mais direitos negados. Pensar o processo de destituição familiar à luz do contexto brasileiro traz à tona elementos como educação, informação, proteção contra o trabalho infantil, moradia, água e saneamento, saúde, bem como a função do Poder Judiciário. O estudo analisa o processo de destituição do poder familiar e seus desdobramentos por meio de marcadores sociais a partir da realização de análise do discurso de petição elaborada pelo Ministério Público.

Palavras-chave: Análise de Discurso; Destituição do poder familiar; Marcadores Sociais; Ministério Público.

\section{DESTITUTION OF FAMILY POWER, SOCIAL MARKERS AND PRECARIETY OF PRIVATE SPACES: DISCURSIVE ANALYSIS OF A PUBLIC PROSECUTOR'S PETITION}

\begin{abstract}
In Brazil, almost 27 million children and adolescents (49.7\% of the total) have one or more rights denied. Thinking about the process of family destitution according to the Brazilian context brings to the light elements such as education, information, protection against child labor, housing, water and sanitation, health, as well as the role of the Judiciary. The study analyzes the process of destitution of family power and its consequences through social markers based on a discourse analysis of a petition written by a Public Prosecutor.
\end{abstract}

Keywords: Discourse Analysis; Destitution of family power; Social Markers; Public Prosecutor.

\section{INTRODUÇÃO}

\footnotetext{
${ }^{1}$ Graduada em Serviço Social pela Universidade do Oeste de Santa Catarina-UNOESC. Especialista em Direitos Fundamentais da Família, Criança e Adolescente pela Universidade do Oeste de Santa Catarina-UNOESC. Discente no Programa de Pós-Graduação Interdisciplinar em Ciências Humanas (Mestrado) da Universidade Federal da Fronteira Sul-UFFS. Assistente Social efetiva no Tribunal de Justiça do Estado de Santa Catarina. Endereço postal: Rua Victor Meirelles, n.317, B. Estrela, São Miguel do Oeste/SC (CEP: 89900-000). Endereço eletrônico: angela_dt@hotmail.com.

${ }^{2}$ Docente adjunta/pesquisadora sênior da Universidade Estadual do Rio Grande do Sul-UERGS. Professora Titular no Programa de Pós-Graduação Stricto Sensu em Direito-UNOESC. Professora Colaboradora no Programa de Pós-graduação Stricto Sensu em Educação da Universidade Estadual do Paraná-UNIOESTE. Avaliadora do INEP-BNI ENADE/MEC. Membro do Comitê Internacional Global Alliance on Media and Gender (GAMAG)-UNESCO. Líder da Linha de Pesquisa Cidadania e Direitos Humanos: perspectivas decoloniais/PPGD-UNOESC. Membro da Rede Brasileira de Educação em Direitos Humanos no Rio Grande do Sul. Membro do Conselho Estadual dos Povos Indígenas (CEPI/Rio Grande do Sul). Endereço eletrônico: t.wencze@terra.com.br.
} 
De acordo com levantamento realizado pela UNICEF (2018), seis em cada dez crianças vivem em situação precária no Brasil, ou seja, cerca de 32,7 milhões de pessoas com até 17 anos expostas a vulnerabilidades. Soma-se a esse universo de situações a desassistência do Estado, as doenças, a fome, acrescidas das privações consideradas "intermediárias" e "extremas", a exemplo da falta de saneamento (com indicadores como a presença de banheiros e rede coletora de esgoto) que prejudica o maior número de crianças e adolescentes (13,3 milhões), seguido por educação (8,8 milhões) e água (7,6 milhões).

Pelos parâmetros utilizados pela Unicef, 61\% dos infantes e dos adolescentes brasileiros vivem na pobreza, seja porque moram em domicílios com renda per capta insuficiente para adquirir uma cesta básica de bens, seja porque têm negado ao menos um dos seguintes direitos básicos: educação, informação, água, saneamento, moradia e proteção contra o trabalho infantil. Os dados analisados no estudo indicam que, dos 53,7 milhões de crianças e adolescentes, 18 milhões (34\%) são afetados pela pobreza monetária - menos de R\$ 346 per capita por mês na zona urbana ou R\$ 269 na zona rural. Desses, 12 milhões (23\%) têm, além de renda insuficiente, um ou mais dos seus direitos básicos negados, integral ou parcialmente.

Nesse contexto, o devido estudo utiliza-se do procedimento metodológico denominadoanálise de discurso com aplicação reflexiva em uma petição inicial emitida pelo Ministério Público em ação de destituição do poder familiar, objetivando identificar as relações estabelecidas pela linguagem do texto com o sujeito que a profere (neste caso, o/a representante da instituição), com a finalidade do documento e a situação em que se produz este discurso. Em especial, demonstram-serecursos discursivos que apontamaspectos relacionados às relações simbólicas (de poder) existentes entre quem profere o discurso e aqueles a quem se direciona, possibilitando a construção de sentidos no contexto em que se insere o documento.

Estas relações se estabelecem tanto em decorrência do papel institucional de acusação, responsabilização e intervenção circunscrito pelo(a) representante do Ministério Público, quanto em razão de diversos outros aspectos históricos, econômicos, políticos, que se estabelecem entre o ente estatal e as pessoas envolvidas na situação em questão. Assim, analisam-se as representações e significações presentes no discurso, a partir deste contexto, especialmente no que se refere à sua finalidade. 
Nessa direção, Orlandi (2000, p. 27) descreve que é a principal responsabilidade do analista ao interpretar aspectos discursivos é a formulação da questão que desencadeia sua análise. Dessa forma, busca-se responder à seguinte questão: quais os elementos linguísticos presentes no texto que retratam a intencionalidade de responsabilização atribuída às pessoas (rés/requeridas) e como ocorre a relação destas representações simbólicas com o contexto em são produzidos socialmente seus sentidos?

Quanto à estrutura, o artigo foi subdividido em cinco partes (capítulos). A primeira (Introdução) aborda a o cenário em que se inserem as crianças e adolescentes envolvidos em situações de vulnerabilidade e violação de direitos, relacionadas aos marcadores apontados nos processos de destituição do poder familiar. O segundo capítulo apresenta reflexões acerca do procedimento metodológico empregado na trajetória de análise que se realiza. No terceiro, é apresentada a contextualização institucional e sociojurídica que possibilita a emissão do discurso presente na petição do Ministério Público e especialmente, a análise discursiva do corpus documental em estudo.No capítulo seguinte (4) se discorre acerca dos elementos de linguagem e contexto sociohistórico de produção do discurso em questão.Na parte final (5) são retomadas as principais conclusões produzidas a partir da elaboração do trabalho (Considerações finais) e em seguida, constam as referências utilizadas na suaconstrução.

\section{SOBRE ANÁLISE DE DISCURSO: REFLEXÕES PONTUAIS}

Para elaboração da análise, recorre-se ao procedimento de análise de discurso apontado por Pêcheux (2006) e Orlandi (2000), os quais utilizam como método a interpretação dos sentidos simbólicos por meio da análise linguística, circunscrita no contexto histórico. ${ }^{3}$ Dessa forma, se busca interpretar o sentido estrito relacionado ao contexto imediato em que se produz o discurso e suas circunstâncias de enunciação - isto é, como se circunscreve no espaço em que é proferido - assim como o sentido amplo, ligado ao contexto sociohistórico e cultural em que é emitido.

Como ensina Orlandi (2000, p.82), "se as novas maneiras de ler, inauguradas pelo dispositivo teórico da análise de discurso, nos indicam que o dizer tem relação com não-dizer,

\footnotetext{
${ }^{3} \mathrm{O}$ método de análise por meio do qual os linguistas propõem novo paradigma para estudo dos discursos pode ser denominado de 'análise do discurso crítica'. Metodologia idealizada inicialmente por Michel Pechêux, que sustenta ser a melhor forma de se interpretar um discurso situando no campo histórico e com bom aceite no campo jurídico.
} 
isso deve ser acolhido metodologicamente e praticado na análise". Nesse viés, a autora também infere que o "não-dizer" tem sido objeto de reflexão de alguns linguistas e cita as reflexões de O. Ducrot (1972, apud ORLANDI, 2000), que buscou distinguir, na origem de sua reflexão, as diferentes formas do não-dizer (implícito), separando aquilo que deriva propriamente da instância da linguagem (pressuposto) daquilo que se dá em contexto (subtendido).

Para isso, analisam-se não só os termos e recursos linguísticos utilizados, como também informações que obtiveram ênfase ou foram atenuadas, o que também se pode nominar como "silêncios" ou "esquecimentos". Orlandi (2000, p.71) destaca que é necessário passar pelas diferentes etapas da análise, indo da superfície linguística ao processo discursivo. Dessa forma, passa-se também pela análise dos esquecimentos e chega-se mais perto do real dos sentidos, na observação das posições dos sujeitos.

Para Foucault o discursoé o resultado daquilo que o sujeito produz em linguagem, 'é um embate entre o sujeito e os saberes', afirmando também que a prática da linguagem não é livre, pois sofre o controle da sociedade, do momento histórico, do mundo social, econômico (instrumentos coercitivos da sociedade). Esse controle causa uma série de discursos que dita quando, como e onde dizer tal coisa. Ele pode ser conceituado como interdiscurso. Foucault acrescenta:

\footnotetext{
O tema da mediação universal é ainda, creio eu, uma maneira de elidir a realidade do discurso. Isto, apesar da aparência. Pois parece, à primeira vista, que ao encontrar em toda parte o movimento de um logos que eleva as singularidades até o conceito de que permite à consciência imediata desenvolver finalmente toda aracionalidade domundo, é o discurso ele próprio que se situa no centro da especulação. Mas este $\operatorname{logos}$, na verdade, não é senão um discurso já pronunciado, ou antes, são as coisas mesmas e os acontecimentos que se tornam insensivelmente discurso, manifestando o segredo desua própria essência. O discurso nada mais é do que a reverberação de uma verdade nascendo diante de seus próprios olhos: e, quando tudo pode, enfim, tomar a forma do discurso, quando tudo pode ser dito e o discurso pode ser dito a propósito de tudo, isso se dá porque todas as coisas, tendo manifestado e intercambiandoseu sentido, podem voltar à interioridade silenciosa da consciência em si. (FOUCAULT, 1999, p.48)
}

Paul Veyne afirma que os coletivos pensam as coisas humanas por meio de ideias gerais que acreditam ser adequadas. Quando nada do que é humano é adequado, racional nem universal e isso surpreende e inquieta o bom-senso, busca-se outro discurso. Ou seja, é igualmente a ilusão reconfortante que nos faz perceber os discursos por meio de ideias gerais, por se desconhecer a diversidade e asingularidade de cada um deles. Pensa-se ordinariamente 
por meio de clichês, por generalidades, "e é por isso que os discursos permanecem para nós ‘inconscientes', escapam à nossa visão”. Portanto, para colocar o discurso a claro, é necessário um trabalho histórico, chamado por Foucault arqueologia ou genealogia. Sobre este aspecto refere Veyne que:

\begin{abstract}
A cada época, os contemporâneos são assim enclausurados em discursos como se estivessem em frascos falsamente transparentes, ignorando quais são esses frascos e mesmo que eles existem. As falsas generalidades e os discursos variam através do tempo; mas, a cada época, eles passam por verdadeiros. Se bem que a verdade reduza-se a"dizer verdadeiro", a falar de acordo ao que se admite ser verdadeiro e que fará sorrir um século mais tarde. (VEYNE, 2008, p.24)
\end{abstract}

Por esta perspectiva, Pêcheux (2006, p.57) aponta que a posição de trabalho que evoca em referência à análise de discurso, supõe que através das descrições regulares de montagens discursivas, se pode detectar os momentos de interpretações enquanto atos que revelam tomadas de posição, reconhecidas como tais, isto é, como efeitos de identificação assumidos e não negados. Orlandi explica que o que interessa ao analista não é o conteúdo, mas a compreensão, por meio deste dispositivo, da forma como o sujeito simbólico constrói e manifesta as significações, produz os sentidos (ORLANDI, 2000, p.25).

Tendo como parâmetro este dispositivo metodológico, realiza-se a análise discursiva dos fragmentos do texto, demonstrando a forma como são produzidos os sentidos explícitos e implícitos no referido documento, revelando possíveis intencionalidades presentes na linguagem utilizada.

\title{
3 ANÁLISE DISCURSIVA DE PETIÇÃO DO MINISTÉRIO PÚBLICO EM AÇÃO DE DESTITUIÇÃO DO PODER FAMILIAR
}

O documento em que se apresenta o discurso em análise foi utilizado para dar início a processo judicial de Destituição do Poder Familiar dos pais (réus/requeridos) em relação aos seus dois filhos (interessados), sendo que um deles já se encontrava em situação de acolhimento (afastado do convívio familiar), mediante determinação em ação judicial anterior (Medida de Proteção). Isto significa dizer que o referido documento foi escrito a partir de informações e ideias anteriores e que, a partir da manifestação do órgão que o emite, são impulsionadas para outros âmbitos institucionais. 
O referido contexto deve ser considerado, pois este tipo de ação judicial só deve ser iniciada a partir de denúncia de grave violação dos direitos dos filhos (pelos pais ou algum deles), ou tendo em vista um histórico de reiteradas violações e negligências, ainda que menos graves. Outros motivos, como a carência de condições socioeconômicas ou questões que não envolvam culpa ou negligência dos responsáveis, legalmente não podem servir para aplicação desta medida. Neste caso, pressupõe a legislação que o grupo familiar seja encaminhado para atendimento, apoio e auxílio por meio das políticas públicas municipais.

Já quando há indicativos de negligências ou riscos aos quais as crianças e adolescentes tenham sido expostos por seus responsáveis, estas informações devem ser encaminhadas ao Ministério Público (MP), que decide, então, por ingressar ou não com a ação que propõe a destituição do poder familiar, ou seja, o rompimento dos vínculos (jurídicos) entre pais e filhos, bem como todas suas consequências. Por ser uma medida drástica, que extingue o parentesco entre pais e filhos, ela só deve ser aplicada ao se verificar que foram esgotadas as medidas anteriores (no âmbito das políticas públicas) para sanar possíveis riscos e violações, viabilizando a manutenção dos vínculos familiares. Este aspecto é primordial porque a interrupção do convívio familiar ainda que em contextos violentadores, é considerada traumática especialmente para os filhos, por isso deve ser encaminhada apenas em casos excepcionais, conforme exposto e preconizado legalmente.

Dessa forma, quando iniciada esta ação, o documento inicial (neste caso, a petição do MP) deve obrigatoriamente apontar elementos considerados passíveis de responsabilização destes pais, a fim de que, ao final do processo, o Poder Judiciário possa decidir pela condenação ou absolvição dos responsáveis, além de outras medidas que visem a proteção dos envolvidos. No caso de condenação, este tipo de ação possibilita que as crianças ou adolescentes destituídos sejam encaminhados para adoção (se viável e benéfico para eles) ou mesmo sua manutenção em serviços de acolhimento, já que indica que o retorno ao ambiente familiar representaria riscos. Neste contexto, são anteriormente avaliadas também as possibilidades de inserção com outros familiares, sempre que possível, pois o benefício da manutenção do convívio familiar também se refere às demais pessoas com quem a criança/adolescente mantinha vínculos afetivos.

Ao iniciar a análise discursiva da peça processual em questão, observa-se que o cabeçalho do documento indica o destinatário da mensagem. Isto é, o texto está sendo direcionado para o Juiz da Vara da Família, Infância e Juventude da comarca. Ou melhor, 
para o "EXCELENTÍSSIMO SENHOR JUIZ DE DIREITO DA VARA", o que demonstra que não se volta especialmente para uma pessoa, mas para o cargo de autoridade por ela exercido.

Logo em seguida, o título em destaque e letras maiúsculas "URGENTE CRIANÇA ACOLHIDA" revela que há uma relação de causa-efeito entre as informações. Isto é, chama atenção para a urgência do que será informado, já que envolve criança em situação de acolhimento (afastada da família). Pressupõe, assim, a prioridade que tal fato exige no rito processual. A mensagem de urgência, ao mesmo tempo, indica também que o tema é grave, pois requer atenção imediata.

O texto começa, então, identificando que quem o profere também o faz em representação a determinado cargo ou posição de poder, neste caso, vê-se: “O Ministério Público, através de seu/sua Promotor(a) de Justiça da Infância e da Juventude desta comarca, no uso de suas atribuições legais [...] vem promover". Aqui, verifica-se a intenção de demonstrar que haveria uma impessoalidade no ato, já que é promovido por um órgão, onde seu representante torna-se um "meio" para aplicação que as funções que lhe são incumbidas por legislações, descritas ao final no mesmo parágrafo.

Dando continuidade ao enunciado, lê-se que o referido emissor promove "a presente AÇÃO DE DESTITUIÇÃO DO PODER FAMILIAR contra [nome pai e dados nascimento e filiação] e [nome mãe, dados nascimento e filiação], residentes na [nome da localidade e município], nesta comarca". Neste sentido, observa-se a utilização do termo "contra" já indica que o texto será direcionado em 'desfavor' dos pais. Acredita-se que se a intenção nesse momento fosse de apontar de forma imparcial os réus, poderiam ter sido usados termos como "em relação à", entretanto, a utilização de "contra", pode estar indicando o verdadeiro objetivo do texto. Ou seja, colocá-los no papel de acusados, como responsáveis pelos fatos que serão apontados em seguida.

Porém, antes de prosseguir com a "acusação contra eles", faz um adendo, entre vírgulas, a fim de assinalaro objetivo de tal procedimento: "com a finalidade de garantir proteção integral às crianças [nome, dados nascimento e filiação] e [nome, dados nascimento e filiação], ambos filhos de [pai e mãe nominados no parágrafo anterior], em razão dos fatos que passa a expor:”. Visualiza-se que neste enunciado, muito mais do que informar sua função de "proteção integral" (conceito jurídico) o MP parece estar realmente justificando sua conduta, ao utilizar "em razão dos fatos que passa a expor”, pressupõe-se que há um contexto 
que será apresentado e justificará a aplicação de uma medida drástica como a destituição do poder familiar.

A descrição dos fatos é exposta a partir da informação "De acordo com a documentação que segue em anexo", ou seja, há uma informação prévia que foi recebida pelo órgão, devidamente "comprovada", pois juntada ao final do texto. Até esta etapa, fica evidente o contexto processual, o rito que envolve uma ação deste tipo, como apontado na introdução do trabalho. Isto é, significa que se trata de uma acusação/denúncia (previamente recebida de outros sujeitos) acerca de condutas ou omissões de responsabilidade dos "pais" ou mesmo executadas por eles, contrapondo o cuidado que é legalmente atribuído aos genitores, segundo a legislação que respalda a intervenção do MP, considerado como aspecto da "proteção integral” dirigida às crianças e adolescentes.

Na verdade, esta proteção integral às crianças e adolescente não é somente dever dos pais ou da família, mas também da sociedade e do Estado. Tal proteção é compreendida, na legislação vigente, como uma corresponsabilidade entre as três instâncias (Estado, sociedade, família), ponto que ainda será abordado em outros trechos do documento.

Na sequência, no mesmo parágrafo, consta que uma das crianças foi acolhida no mês anterior, porque "se encontrava em situação de abandono e com seus direitos violados". E o texto prossegue utilizando termos genéricos indicando que "após intervenção", verificou-se que o irmão, que continua residindo com a família "também se encontra com seus direitos ameaçados" e então, uma das chaves centrais até aqui, finaliza: "em razão da conduta dos requeridos, seus genitores". Nesta parte que introduz a argumentação que o representante do MP passará a discorrer, visualiza-se, de forma clara, a utilização da linguagem de forma a atribuir aos pais a culpabilidade pelas ameaças e violações de direitos às quais os filhos teriam sido expostos, verificadas por meio de "intervenção" de sujeitos ou órgãos não especificados.

A partir dos parágrafos seguintes são abordadas justamente estas intervenções e informações prestadas ao MP e que justificam a representação contra os pais ("instruem a inicial"). Nas duas páginas que seguem, destacam-se elementos que atribuem aos pais a responsabilidade no âmbito familiar privado, ao mesmo tempo que buscam demonstrar a isenção de responsabilidade pública sobre o contexto vivenciado pelo grupo familiar, reforçando a todo momento a idéia de que "já foram esgotadas" medidas anteriores, como condiciona a legislação pertinente. 
O parágrafo imediatamente seguinte ao último apontado, indica justamente esse quadro, quando expõe que "os requeridos não demonstraram zelo para com a saúde dos filhos, não comparecendo às consultas e não realizando exames e vacinas necessários à preservação da saúde das crianças". Nesta frase, pode-se observar que "zelo" é empregado no sentido de algo que deve ser demonstrado, por meio do comparecimento a consultas e agendamentos realizados pelos serviços públicos.

Denota-se que esta é a compreensão de zelo e cuidados considerada pelos representantes não só do MP, mas da unidade básica de saúde, do Conselho Tutelar e de diversas "instituições" que ocupam a posição de "avaliação" da família, naquele momento. Dessa forma, reforçam a idéia de que a família tem sido "negligente" por não estarem cumprindo com estes compromissos, já que "vem sendo acompanhados pelos referidos serviços e "demais órgãos" há anos. Trecho que também é empregado para destacar a atuação dos órgãos públicos, isentando-os de responsabilidade sobre a situação de saúde das crianças, deixando subentendido que seu papel era o de "agendar e oferecer os serviços", o qual foi cumprido e o resultado não foi alcançado porque a família não teria se comprometido em levá-los aos atendimentos.

Esta representação acerca da falta de "zelo", ou "negligência" é observada em diversos outros trechos do documento, sempre trazendo a tona os sentidos atribuídos pelas referidas instituições, ou melhor, pelas pessoas (profissionais) em exercício de funções nestes locais. No parágrafo seguinte, se identifica, além da individualização da "culpa" na família, que há uma individualização do papel de cuidados especialmente sobre a genitora, pois aponta que "o requerido trabalha temporariamente [...] e a requerida, embora responsável pelo cuidado com os filhos e com a casa, é totalmente negligente para com suas obrigações”. Aqui o emprego da expressão "embora" denota justamente que há uma concepção prévia de qual seriam as "obrigações" de uma mãe (e "dona de casa"/desempregada"), as quais ela não atende, pois considerada "totalmente negligente" em relação a tais expectativas.

Este contexto de expectativas dos órgãos que não são atendidas pela família, reaparece de forma clara no parágrafo seguinte, onde se lê: "foi observado ausência de cuidados com a higiene da casa, na qual circulavam animais (galinhas, cachorros e gatos)". Percebe-se, neste aspecto, que há um sentido culturalmente atribuído pelos emissores das informações sobre a ideia de higiene, no qual a presença de animais significa ausência de cuidados com higiene. Da mesma forma, logo em seguida, o conceito de higiene é relacionado 
à condição de salubridade ao descrever o ambiente externo da casa, indicando outra vez uma pré concepção não atendida: "verificou-se a existência de muito lixo e água podre parada, inexistindo condições para que ali as crianças pudessem se desenvolver de maneira saudável". 4

Ainda nesta frase, pode-se identificar a questão da culpabilização dos pais por algum cuidado que não ofereceram aos filhos, já que o ambiente insalubre não é considerado ruim para a família toda, mas para "as crianças". Ou seja, fica subentendido que há exigências diferentes de higiene para que uma criança ou um adulto habitem o mesmo ambiente, ou ainda, há uma preocupação somente com o fato de haverem crianças neste local e não se abordam possíveis implicações destas condições para os demais membros, já que se busca reforçar a ideia de culpabilidade, em detrimento da proposição de ações, por parte da família ou mesmo dos serviços públicos, para saná-las. Os entes públicos, neste ponto, não são citados sequer para dizer o que pode já ter sido feito para evitar tal situação, somente se alude que ocorreram "visitas à residência" onde foram apenas constatadas todas as questões de higiene e insalubridade pontuadas.

As diferentes expectativas de comportamentos para cada membro da família são também verificadas adiante, onde se aponta que "A alimentação era preparada pelo requerido que ao chegar do trabalho tinha que cozinhar os alimentos para a família". O emprego da expressão "tinha" demonstra que esta situação representa um esforço, algo considerado difícil ou absurdo, deixando em suspenso a ideia de que seria inadequado que ele precisasse fazer isso, ao chegar do trabalho. Este ponto pode também estar ligado à questão de papéis familiares anteriormente apontada, já que enquanto o pai/marido estava no trabalho, a esposa e mãe das crianças não cumpria com a atribuição esperada dela, de cozinhar para a família, corroborando com a narrativa que vai sendo apresentada e transmitindo a ideia de negligênciapor parte da mãe enquanto cuidadora. Constata-se aqui uma relação de 'obrigação' da mulher mãe para com o exercício da maternidade.

Estes "deveres" atribuídos social e culturalmente à mãe e à esposa também se evidenciam no parágrafo seguinte, onde consta que "A requerida, por sua vez, passava a maior parte do tempo dormindo ou na rua, sendo que já havia anteriormente saído de casa e

\footnotetext{
${ }^{4}$ Insta destacar que de acordo com o IBGE (2020), há no país mais de 5,1 milhões de domicílios em condições precárias. Eles fazem parte de mais de 13,1 mil aglomerados subnormais, que são formas de ocupação irregular de terrenos. Os aglomerados subnormais são conhecidos no Brasil por denominações que variam de acordo com a região. Favela, invasão, grota, baixada, comunidade, mocambo, palafita, loteamento, ressaca e vila são algumas das denominações populares pelas quais eles são conhecidos.
} 
abandonado o marido e os filhos pequenos." Pode-se compreender, nesta construção de sentidos, que a mãe/esposa aparece como algo destacado do restante do contexto já apontado. Isso se expressa em "por sua vez", ou seja, ela é algo a parte dos demais fatores e papéis que lhe cercam, de quem se espera que não passe a maior parte do tempo dormindo, não fique na rua. Tais pontos aparecem relacionados com o "abandono" dos filhos e marido, considerados de forma conjunta como dependentes dela (ou de seus cuidados), pois ambos figuram como abandonados e assim, se conclui que ela não exerceu adequadamente suas funções (ao menos para os padrões dos emissores do texto).

Mais adiante, relata-se a ocasião em que uma das crianças havia sido deixada com um casal, situação que foi classificada como abandono e levou ao seu acolhimento. Destacamse os trechos: "Em relação a [nome] informou se que foi entregue ao casal sem documentos nem roupas, muito suja e cheia de piolhos" ${ }^{\text {; }}$ e "O requerido [nome do pai] alegou que precisava trabalhar, que não recebia ajuda dos familiares e que a requerida [nome da mãe] não mostrava interesse em cuidar da saúde, higiene e educação da filha [nome].” Nessas frases são retomados os aspectos higienistas já apontados anteriormente, bem como a divisão de expectativas entre os papéis familiares. Este ponto se revela pela associação novamente das questões de saúde, higiene, educação dos filhos ao interesse da mãe, enquanto que o pai "precisava trabalhar" e não se menciona o interesse do pai, mas sim a expectativa de que a mãe cumprisse tais funções.

Além disso, vê-se, pela primeira vez no documento, uma fala atribuída àqueles de quem se está tratando. No caso, dá-se voz (ainda que de defesa) ao pai, quando se registra que ele "alegou" que precisava trabalhar. Entretanto, o mesmo não ocorre com a mãe, de quem muito se fala, mas cuja opinião, justificativas e manifestações não são descritas. Consta no documento apenas o que o marido e os profissionais indicam sobre ela e até mesmo o que estes supõem sobre suas vontades e interesses (verificou-se, foi observado, demonstrou, etc.), isto é, sempre impressões ou conclusões daqueles que detém, aparentemente, o poder de dizer a verdade dos fatos e até mesmo de interpretar a subjetividade do outro.

Na sequência do texto, há um parágrafo especialmente dedicado a analisar a situação de saúde da mãe, porém sob o ponto de vista de suas capacidades, não de suas necessidades, como ocorreu quando se abordou as condições de saúde das crianças. Onde se lê que "a

\footnotetext{
${ }^{5}$ Segundo a OMS (2019), grande parte das doenças que atingem as crianças brasileiras de 0 a 5 cinco anos são derivadas da falta de acesso à água de qualidade e ao saneamento precário.
} 
requerida deveria realizar acompanhamento psiquiátrico e não faz uso da medicação de forma correta", se identifica diversas omissões, como: porque deveria realizar o acompanhamento? Porque não usa a medicação corretamente? Segundo quais informações, ela deveria fazer esse tratamento? Questiona-se, diante desses silêncios, porque quando se fala das crianças a todo momento é retomada a autoridade de quem emitiu as informações para demonstrar suas necessidades, enquanto que ao falar da mãe apenas se afirmam as obrigações que ela deixa de cumprir em relação ao seu autocuidado?

Acredita-se que a frase subsequente dá as pistas de qual a finalidade destes destaques e silenciamentos: "além de ser diagnosticada com [doença grave], iniciando em breve o tratamento necessário, o que muito possivelmente a deixará mais debilitada para cuidar dos filhos e da casa." Ou seja, pela forma como foi encadeada a frase, vislumbra-se que a doença está sendo também usada como argumento que comprova a incapacidade de a mãe cuidar dos filhos no futuro, como se ela mesma fosse responsável por seu quadro de saúde (não faz uso de medicação psiquiátrica..., além de ter sido diagnosticada com a patologia) e como se o diagnóstico fosse também uma "opção", assim como não tomar remédios e não fazer o acompanhamento psiquiátrico, apontados na mesma linha de raciocínio e sequencialmente no texto (e sem explicar o porquê ou apontar maiores detalhes).

Tal intencionalidade revela-se também pela omissão, novamente, de qualquer aspecto relativo ao suporte dos serviços para que a família consiga se reorganizar e dar conta dos cuidados dos filhos e do autocuidado, uma vez que o pai trabalha e a mãe está doente e nada mais se comenta sobre possíveis auxílios para que enfrentem tais dificuldades. Somente se destacam as limitações dos pais - elencando-seos fatores de sua incapacidade, no âmbito individual ou familiar privado - para suprir as necessidades e proteger os filhos de violações, contribuindo assim para que as limitações sejam observadas como negligências, desleixo, desinteresse.

Nesse sentido, identificam-se também algumas contradições ou distorções, que podem estar relacionadas ao objetivo de enfatizar as responsabilidades familiares e atenuar a ausência dos serviços públicos ou suainefetividade (por razões tampouco clarificadas). Isso porque, na sequência do documento, consta que "A criança [nome] que frequenta a Associação de Pais e Amigos dos Excepcionais (APAE) de [nome cidade] desde [ano], onde realiza acompanhamentos de Fisioterapia, Terapia Ocupacional e Fonoaudiologia, está exposto a situação de violação de direitos, já que no mês de [...] informou-se que faziam duas 
semanas que a criança não era mais levada aos atendimentos na APAE." A contradição se verifica pela informação de que a criança tem feito diversos acompanhamentos durante os últimos anos, ao mesmo tempo que se busca demonstrar que está em risco por não fazer este acompanhamento nas últimas duas semanas, corroborando, dessa forma, para a tese de que os pais são negligentes com sua saúde (sentido conferido aos argumentos apontados anteriormente).

Ao mesmo tempo, nesse contexto, se suprime a relação entre os fatos, colocados como uma lista sequencial de aspectos negativos, observados nas iniciais de cada parágrafo ou frase (de acordo com..; segundo informações...; em data.., no mês de...). Enquanto que se poderia elaborar o texto de forma que seja compreensível, por exemplo, que recentemente a mãe descobriu a grave doença que lhe acomete e nesse período o filho não foi às consultas e atendimentos da APAE (pois as informações referem-se ao mesmo mês). Em vez disso, busca-se distorcer as correlações para, novamente, colocar os pais como responsáveis exclusivamente, em razão de sua vontade (ou falta), por não atenderem às necessidades dos filhos e, assim, colocá-los em situação de violação de direitos.

Ao final da arguição, éretomada a afirmativa que vem sendo sustentada, de modo geral: "Muito embora os requeridos tenham recebido auxílio e orientação do Conselho Tutelar e demais serviços socioassistenciais do município, demonstraram não possuir condições para exercer as responsabilidades inerentes ao poder familiar." Vislumbra-se, sobretudo, o reforço da idéia de não atendimento à expectativa ou papel esperado, expresso em "muito embora.... não demonstraram condições". Isto é, não atenderam àquilo que o(a) representante do MP avaliou como condições para exercício do poder familiar. O que deixa claro que há um contexto institucional, possibilitado por estruturas legais e culturalmente impostas ou aceitas, que coloca o representante do referido órgão na posição de "acusar" o descumprimento destas prerrogativas, sob o pretexto de proteção das vítimas de tal descumprimento.

A última frase emitida antes das proposições finais do documento, reitera esse cenário de atribuições simbolicamente atribuídas à figura do(a) Promotor(a) de Justiça, de ser quem "interpreta" a legislação, segundo suas concepções, tidas como verdadeiras: "A entrega da criança [nome], da maneira como realizada, a um casal sem qualquer vínculo familiar e sobre o qual pouco os requeridos sabiam, caracteriza-se como abandono". Significa dizer que, para o(a) operador(a) do direito, "no uso de suas atribuições", deixar a filha com o casal (que em seguida foi informada aos órgãos de proteção pela própria mãe), é considerado abandono. 
O abandono, por sua vez, é legalmente enquadrado como prerrogativa para a perda do poder familiar, desde que "não justificado", assim como os pode ocorrer com outros "descumprimentos" dos deveres parentais.

\section{APONTAMENTOS ANALÍticos A PARTIR dO LOCUS DE EMISSÃo E CONTEXTO SOCIOHISTÓRICO DE PRODUÇÃO DO DISCURSO}

A partir dos aspectos apresentados, cabe apontar que o documentoem análise revela um espaço social onde as representações das pessoas a quem se dirige o discurso emitido não são consideradas válidas. Essa questão se demonstra pela forma como a linguagem é construída no texto, a exemplo do trecho em que se aborda que a própria genitora/ré avisa o Conselho Tutelar que deixou a filha com um casal porque não estava conseguindo cuidar dela: "Em data de [...] a requerida informou ao Conselho Tutelar que não possuía condições de cuidar da filha [nome], razão pela qual esta teria sido entregue ao casal [...]”. Neste ponto, denota-se que seria possível interpretar-se tal ato como uma medida responsável, talvez um pedido de ajuda; ou pelo menos considerar que nas representações subjetivas da família, isso não seja compreendido como abandono.

Contudo, toma-se o ato como abandono, partindo-se de premissas jurídicas e até morais válidas na concepção daqueles que detêm o poder e função conferida cultural e legalmente para elaborar o documento e apontar medidas a serem tomadas a partir das informações enunciadas.Em vez disso, assim como todo o contexto que cerca o grupo familiar (vulnerabilidade econômica, precariedade de condições da habitação, problemas de saúde), tal ponto foi somado àqueles compreendidos como omissões voluntárias e assim, enquadrados como "abandono, negligência e descumprimento injustificado dos deveres e obrigações de que trata o artigo 22 do Estatuto da Criança e do Adolescente", o que pode, então, justificar a aplicação de medidas judiciais drásticas em desfavor dos pais ou responsáveis.

O arcabouço legal, segundo interpretado pelo emissor, é também pontuado em outros trechos, a fim de demonstrar sua função e exercer os poderes inerentes a ela. Como se pode observar no recorte: "diante da violação dos direitos fundamentais das crianças reconhecidos pela Constituição Federal e pelo Estatuto da Criança e Adolescente, o Ministério Público, com fulcro no disposto nos artigos $4^{\circ}, 7^{\circ}, 22,24$ e 155 a 163 da Lei ${ }^{\circ} 8.069 / 90$ e artigo 1.638 , do Código Civil, requer [...]", especialmente pelo uso dos termos "diante da violação" 
(interpretação subjetiva) e "com fulcro no disposto nos artigos" (poder atribuído pelo exercício da função).

E ao final, onde se descreve que o órgão representado "requer", então, todas as medidas comumente atribuídas a este tipo de ação, também baseadas na legislação vigente acolhimento das crianças, designação de audiências para oitiva dos envolvidos, avaliações psicológicas e sociais - e ainda, que o(a) Juiz(a) da Vara destinatária do documentodecrete a perda do poder familiar, intenção defendida pelos argumentos apresentados desde o início da construção narrativa. Evidente que não seria possível que constassem todas as informações de uma situação e seu histórico num único documento, o que certamente ampliaria as perspectivas de análise.

No texto do documento analisado, inclusive, foi reconhecida também a necessidade de novas "intervenções" (avaliações daquela realidade), a fim de subsidiar as decisões judiciais durante a instrução processual. Contudo, buscando-se estudos já realizados acerca deste tipo de ação processual e das concepções dos profissionais dos que atuam nestas situações, o que se verificou é que os diversos atores/sujeitos deste contexto, reproduzem “discursos de 'verdades' sobre as famílias e de normatização de suas vidas [...], bem como o fundo de punição de seus atos com a retirada dos filhos" (CÓRDOVA, BONAMIGO, 2012, p.155).

Ou seja, sob o escopo da proteção e garantia de direitos, muitas vezes acaba sendo reproduzida uma lógica na qual o acesso aos direitos é acionado pela via judicial, pois não é garantido no âmbito das políticas públicas, fenômeno conhecido no campo jurídico e das ciências sociais como "judicialização dos conflitos sociais", "das políticas sociais", ou ainda “da questão social” (BORGIANNI, 2013, p.426). Neste contexto, pode-se dizer que a judicialização reflete um caráter contraditório, pois pode ser tanto uma alternativa para a efetivação de direitos, como pode reforçar a tendência do Judiciário em aplicar seu poder de forma repressiva e culpabilizante das famílias (SIERRA, 2014).

Nessa perspectiva, a judicialização das demandas que geram a destituição do poder familiar, retrata um processo de responsabilização e culpabilização dos indivíduos e dos núcleos familiares por situações de desproteção social e de risco. Na atual conjuntura (neoliberal) de desmonte de direitos e de banalização da vida humana, a tendência é que o fenômeno se acentue e amplie, o que revela a ocorrência de uma violência institucional, à medida que representa a banalização da vida da população, por meio de movimentos e 
relações de poder utilizadas de forma repressora, sem uma análise crítica da realidade social (FÁVERO, 2018, p.65).

Este quadro se configura também no contexto em análise, onde se constata a prevalência de questões culturais que são reproduzidasno âmbito institucional, em relação ao papel da mulher/mãe como cuidadora dos filhos, e do homem/pai responsabilizado basicamente pelo seu sustento, desconsiderando as dificuldades de ambos para acessar políticas públicas, emprego, renda, ou mesmo suas condições de ter autonomia. Nesse ponto, identifica-se a presença da herança cultural colonial homogeneizante e violentadora, escondida sob a pretensão de teorias democráticas universais (MIGNOLO, 2008), nas quais se ancoram ainda hoje os dispositivos legais dos países que sofreram o processo de colonizaçãopelo norte europeu.

Tais representações afetam a subjetividade dos povos colonizados e consequentemente, são ainda retratados nas regulamentações, nas políticas estatais perpassam as representações daqueles que atuam nestes setores, se tornando ainda mais visíveis em espaços de poder, como este em que é proferido o discurso analisado. A herança desta racionalidade pode ser atualmente percebida nos diferentes âmbitos e espaços, disseminados em nível mundial por meio do padrão de poder capitalista globalizado, segundo Quijano (2005, p.123). Dentre esses âmbitos, cabe aqui destacar:

"[...] no controle do trabalho, de seus recursos e de seus produtos, está a empresa capitalista; no controle do sexo, de seus recursos e produtos, a família burguesa; no controle da autoridade, seus recursos e produtos, o Estado-nação; no controle da intersubjetividade, o eurocentrismo[...]. (QUIJANO, 2005, p.123)

Nessa direção, evidencia-se no discurso institucionalizado pelo Ministério Público, assim como por outros entes do poder estatal, um espaço onde emergem concepções e racionalidades consideradas referências universais. Entretanto, tais parâmetros se revelam amplamente colonizadas pelo ideal eurocêntrico e por referências de desenvolvimento oriundas do norte global, onde a família heteronormativa patriarcal branca é considerada um padrão de "normalidade", bem como sua cultura (religião, hábitos, crenças), sua forma de inserção na divisão social do trabalho (padrões de estabilidade, acumulação), sua organização no âmbito privadofamiliar (funções parentais e comunitárias baseadas numa divisão sexual das atividades). 
Tais representações acabam sendo mascaradas por um arcabouço legal e político que aparenta uma superficial igualdade de direitos e democratização de seu acesso, mas que acabam promovendo um apagamento ou invalidação de formas de subjetividade, culturas e referências. A partir destes aspectos em análise, sublinha-se que apesar dos significativos avanços no plano normativo referente às garantias dos direitos sociais e humanos, revelam-se também as limitações que o aparato estatal tem encontrado para efetivar tais garantias.

O que se evidencia a partir destes contextos em que são construídos os sentidos expressados no documento analisado, é que as vias e políticas de acesso ou execução dos direitos fundamentais tem se restringido a proporcionar uma minimização das mazelas sociais, enquanto se reproduz a concepção ocidental mecanicista onde direitos pressupõem deveres, em vez de estarem fundamentados basicamente na condição humana. Isto é, ao mesmo tempo em que se opera uma política estatal padronizada e de estrutura clientelista, deposita-se no indivíduo a responsabilidade individual sobre sua condição estrutural, promovendo um discurso que o culpa por não conseguir superar suas dificuldades ou alcançar a independência em relação aos serviços estatais.

\section{CONSIDERAÇÕES FINAIS}

$\mathrm{Na}$ elaboração da presente análise, percebe-se que ao analisar as condições de produção dos sentidos por meio da linguagem empregada no documento emitido pelo Ministério Público, estes aspectos acabaram se refletindo também na abordagem do conteúdo trazido pelo texto. Inicialmente observa-se um conjunto de representações que colocam a família como uma instância de atendimento das necessidades dos filhos. Os pais, e especialmente a mãe, são considerados basicamente sob o aspecto das competências que lhe são atribuídas, não somente pelo(a) representante da instituição Ministério Público, mas interpretadas pela subjetividade do conjunto de profissionais que fornecem informações ao referido órgão. Tal contexto se manifesta no âmbito do Poder Judiciário, de onde social e culturalmente se considera que estas intervenções são baseadas em pressupostos legais, que colocam os emissores na posição de "avaliadores" das competências parentais.

Estas representações se revelam por um discurso no qual as subjetividades oriundas daqueles de quem se trata o texto são apagadas. Ou seja, parte-se de uma referência 
universalmente aceita de expectativas em torno dos papéis familiares e passa-se a enumerar os aspectos (considerados negativos) que não foram adequadamente alcançados. Utiliza-se de conclusões daqueles que possuem "a voz" considerada "verdadeira", para estabelecer olhares culpabilizantes, a fim de responsabilizar os pais por questões interpretadas como de sua vontade ou escolha (condições estruturais do ambiente e território residencial, cuidados de saúde e higiene, não comparecimentos aos serviços oferecidos e até mesmo condições de saúde/doenças dos membros do grupo familiar).

Na mesma proporção que se responsabiliza, no âmbito individual ou familiar, os pais pelas carências e violações às quais os filhos estão expostos, se busca atenuar a corresponsabilidade de outros entes no atendimento de necessidades que são de todo o grupo familiar, não somente das crianças. Nesse sentido, verificam-se diversos termos empregados com a finalidade de indicar que houve a intervenção, apoio e atuação dos serviços públicos por anos, mas que os pais sãounicamente responsabilizados pelo fracasso destas ações, tendo em vista que se conclui, a cada "falha", que eles e sobretudo a mãe, não exerceram adequadamente suas funções (cujos padrões são baseados na interpretação da lei realizada pelos emissores do texto).

Os pais, ou genitores (no termo jurídico que também transmite uma idéia de distanciamento afetivo em relação aos filhos), são retratados como únicos causadores das questões que afetam os filhos e assim, responsáveis por colocá-los em situação de violação de direitos. Fica subentendido, inclusive, que fazem isso intencionalmente, pois a todo momento reforça-se que são negligentes, descuidados e receberam o suporte necessário pelos serviços públicos, entretanto o pai "trabalhava" e mãe "não tinha interesse" nos cuidados básicos dos filhos e ambiente doméstico. São silenciados, contudo, os motivosou mesmo as manifestações que dizem respeito aospróprios interesses e compreensões das pessoas de quem se fala no texto.

O discurso produzido é construído a partir de pressupostos legais, culturais, morais e socialmente válidos, para os quaishá um modo de vidaposto como "padrão", que se traduz na atribuição de papéis sociais e familiares pré-definidos com base no sexo, na divisão social do trabalho e em diversas exigências compreendidas como ideais de cuidado, de relações e de condições de vida. Os parâmetros que constroem estas expectativas se revelamdistantes das profundas desigualdades e marcadores sociais brasileiros, bem como refutam os processos de colonialismo e colonialidade impostos à nação. 
Este processo, segundo os autores referenciados, foi executado por meio do extermínio de povos e culturas e da imposição de um novo modo global de produção e relações sociais que possibilita(ra)m a disseminação e reprodução desse sistema (nas relações pessoais, de gênero, de trabalho e classe, na organização familiar e social, entre outras instâncias da subjetividade).Identificou-se, então, que estas representações afetam fundamentalmente as relações de poder em nível global, assim como a subjetividade das estruturas sociais que se formam a partir destas relações. Assim, demonstrou-se o trajeto e a herança que permanecem sendo reiteradas nas relações estado-cidadãos atualmente, perpetuando exigências incompatíveis com a realidade subalternizada e reproduzindo relações de poder opressoras, homogeneizantes e culpabilizantes, ao passo que exime cada vez mais o Estado capitalista e neoliberal de sua corresponsabilidade.

O referido cenário corrobora, contraditoriamente, para que o acesso aos direitos seja perpassado sobretudo pela esfera judicial, evidenciando a redução das garantias no âmbito administrativo e ao mesmo tempo, a reprodução do discurso normativo do âmbito familiar privado, que mascara a perspectiva de redução dos direitos e de culpabilização e responsabilização/punição dos pais pelas condições estruturais a que (eles e) seus filhos encontrem-se submetidos. Vislumbrou-se, a partir destes aspectos, a emergência de suplantar as contradições entre os discursos constitucionais e a viabilização destas garantias, superando o modelo de desenvolvimento que se busca aplicar em povos colonizados e subalternizados, as custas do apagamento de sua subjetividade e da invalidação de outras formas de vivências e de relações.

\section{REFERÊNCIAS}

BORGIANNI, Elisabete. Para Entender o Serviço Social na Área Sociojurídica. Serviço Social \& Sociedade [online], 2013, n.115, p.407-442. Disponível em: https://doi.org/10.1590/S0101-66282013000300002. Acesso em 10 out. 2020.

CÓRDOVA, Mara Fernanda; BONAMIGO, Irme Salete. Filhos Afastados de suas Famílias: Ações e concepções dos profissionais. In: Polis e Psique, Vol.2, n.1, p. 137-156. 2012. Disponível em: https://seer.ufrgs.br/PolisePsique/article/download/29238/25709. Acesso em 09 set. 2020.

FAVERO, Eunice Terezinha. Serviço Social no Sociojurídico: requisições conservadoras e resistências na defesa de direitos. Serviço Social e Sociedade, n. 131, São Paulo, jan./abr. 2018. Disponível em: https://www.scielo.br/scielo.php?script=sci arttext\&pid=S0101$\underline{66282018000100051 \& \operatorname{lng}=p t \& n r m=i s \& t \operatorname{lng}=p t}$. Acesso em 10 set. 2020. 
FOUCAULT, Michel. A Ordem do Discurso: aula inaugural no College de France, pronunciada em 2 de dezembro de 1970. Tradução Laura Fraga de Almeida Sampaio. $5^{\mathrm{a}}$ ed. São Paulo: Loyola, 1999.

IBGE. Aglomerados Subnormais 2019: Classificação Preliminar e informações de saúde para o enfrentamento à COVID-19. Nota técnica 01/2020: 19 de maio de 2020. Ministério da Economia, Instituto Brasileiro de Geografia e Estatística - IBGE, Diretoria de Geociências Coordenação de Geografia. Rio de Janeiro, 2020. Disponível em:

https://biblioteca.ibge.gov.br/visualizacao/livros/liv101717_notas_tecnicas.pdf. Acesso em 11 out. 2020.

MIGNOLO, Walter. Desobediência Epistêmica: a opção descolonial e o significado de identidade em política. Cadernos de Letras da UFF - Dossiê: Literatura, língua e identidade, n.34, p.287-324. Niterói, 2008. Disponível em:

http://www.cadernosdeletras.uff.br/joomla/images/stories/edicoes/34/traducao.pdf. Acesso em 11 set. 2020.

SIERRA, Vânia Morales. O Poder Judiciário e o Serviço Social na judicialização da política e da questão social. Ser Social, v. 16, n. 34, 2014, p. 30-45. Disponível em:

https://periodicos.unb.br/index.php/SER Social/issue/view/1203. Acesso em 09 set. 2020.

OMS. Relatório Setorial de Saúde -Brasil. Disponível em:

https://www.who.int/eportuguese/publications/pt/.Acesso em: 14 set. 2020.

ORLANDI, Eni Puccinelli. Análise do Discurso: Princípios e procedimentos. Campinas, SP: Pontes, 2000.

PÊCHEUX, Michel. O Discurso: Estrutura ou Acontecimento. Campinas, $4^{\mathrm{a}}$ edição, SP: Pontes, 2006.

QUIJANO, Aníbal. Colonialidade do Poder, Eurocentrismo e América Latina. A

Colonialidade do Saber: Eurocentrismo e Ciências Sociais. Perspectivas latinoamericanas. Edgardo Lander (org). ColecciónSurSur, CLACSO, Buenos Aires, 2005. p.116142. Disponível em: http://biblioteca.clacso.edu.ar/clacso/sur-

sur/20100624103322/12_Quijano.pdf. Acesso em 11 set. 2020.

UNICEF. Relatório Pobreza na Infância e na Adolescência. Brasil: Imprensa Oficial. Disponível em:

https://crianca.mppr.mp.br/arquivos/File/publi/unicef/pobreza na infancia e na adolescenci a_unicef_2018.pdf . Acesso em: 14 set. 2020.

VEYNE, Paul. Foucault: Sa pensée, Sapersonne. Paris: Albin Michel, 2008. Tradução das autoras. 